\title{
A igualdade através da diferença e as estratégias de reconhecimento do movimento nacional dos catadores de materiais recicláveis (MCNR)
}

The equality through difference and the recognition strategies of the recyclable materials collectors nacional movement/BRASIL (MNCR)

\section{Cristiano Benites Oliveira}

Universidade do Vale do Rio dos Sinos - UNISINOS - São Leopoldo - Rio Grande do Sul - Brasil

\begin{abstract}
Resumo: As discussões sobre o conceito de reconhecimento trazem em seu escopo importantes aportes teóricos para que se possa compreender e interpretar o desenvolvimento das estratégias de conflito protagonizadas pelo Movimento Nacional dos Catadores de Materiais Recicláveis (MNCR). O potencial interpretativo da concepção de reconhecimento, aqui debatida, reside na possibilidade de equacionamento de forma efetiva das discussões sobre igualdade e diferença no interior dos processos estratégicos traçados pelo referido movimento em contextos marcados por grandes desigualdades em termos sociais, políticos e econômicos. Este artigo também problematiza a importância do processo de ambientalização dos catadores de materiais recicláveis como forma de encaminhar a questão do reconhecimento desses sujeitos.
\end{abstract}

Palavras-chave: Estratégias de reconhecimento. Identidade pessoal. Principio de igualdade.

Abstract: The discussions on the concept of recognition bring in their scope important theoretical contributions to understand and interpret the development of conflict strategies performed by the National Movement of Recyclable Materials (MNCR). The interpretive potential of concept recognition, discussed here, is the possibility of effectively addressing the discussions about equality and difference within the strategic processes outlined by this movement in urban contexts marked by huge inequalities in social, political and economic terms. This article still discusses the importance of environmenting process of recyclable materials collectors in order to refer the issue of recognition of these subjects.

Keywords: Recognition strategies. Personal identity. Egalitarian ethics. 


\section{Introdução}

A ideia de reconhecimento tem sido reivindicada como plataforma sociopolítica por diversos movimentos sociais, os quais têm pautado suas estratégias de atuação por esta noção, como um meio de superar o tratamento discriminatório, o qual mantém e reforça as diversas formas de desigualdade. Mas qual é o sentido teórico desta noção, e quais são as consequências políticas e estratégicas para desenvolvimento político e histórico dos atores coletivos inseridos em contextos desiguais? Motivado por esta problemática, este artigo tem por objetivo abordar as discussões sobre as estratégias que visam à conquista de reconhecimento social levadas a cabo por catadores de materiais recicláveis organizados no Movimento Nacional dos Catadores de Materiais Recicláveis (MNCR). O que se pretende é aprofundar a reflexão tanto teórica quanto política como forma de qualificar o debate a respeito de como as desigualdades podem ser minimizadas através do processo de reafirmação de diferenças por parte dos catadores de materiais recicláveis.

Nos últimos anos, os catadores de materiais recicláveis do MNCR têm pautado suas estratégias pela conquista do reconhecimento. Isso pode ser constatado em uma de suas cartilhas de formação política, em que consta: "A luta pelo reconhecimento da categoria de catador, em todas as esferas, e a luta por condições dignas de trabalho, estão fundamentadas no direito ao trabalho" (MNCR, 2010, p. 14, grifo do autor). Essa luta vem engendrando conflitos contra os processos de discriminação desses sujeitos. Tal conflitualidade deve ser entendida como uma ameaça contra as identidades pessoais dos catadores, as quais são constituídas pelas suas relações de trabalho e de produção.

A compreensão das estratégias de conflito empregadas por esses catadores para a conquista de seu reconhecimento passa pelo aprimoramento das perspectivas políticas desta categoria. Como forma de tematizar esse processo de desenvolvimento histórico dos catadores na luta pelo seu reconhecimento, é de grande importância também estabelecer um debate teórico a cerca das estratégias de combate às desigualdades através da reafirmação de aspectos identitários e coletivos desses sujeitos. Para isso, neste artigo busca-se aplicar o debate de alguns conceitos básicos das teorias do reconhecimento, enquanto uma forma de potencializar o aporte teórico sobre os processos de enfrentamento às desigualdades engendradas por discriminações de catadores no âmbito da reciclagem realizada pelos mesmos.

Como forma de realizar este debate, o que se pretende refletir criticamente é a hipótese sustentada por Silva e Michelotti (2009, p. 448) de que a luta estratégica por reconhecimento dos catadores de materiais recicláveis não tende a orientar-se pelo princípio de igualdade, característico da era moderna, mas ser conduzida por esforços empreendidos pelo MNCR para "acessar e usufruir privilégios associados às posições diferenciadas que configuram a hierarquia social". No caso dos catadores, o processo de legitimação de desigualdade ocorreria no momento em que eles visassem a ambientalização de suas atividades ao invés da busca pela igualdade entre todos os catadores.

Apesar de sua aparente plausibilidade, uma interpretação mais aprofundada através do debate teórico e conceitual no interior da teoria do reconhecimento pode demonstrar as insuficiências da referida pressuposição. Como forma de discussão de tais insuficiências e com a finalidade de suscitar o debate teórico-estratégico, primeiramente, realizar-seá uma breve discussão sobre a perspectiva dualista defendida por Nancy Fraser (2006). Em segundo lugar, serão tratadas as fontes sociais do sofrimento e do descontentamento dos catadores como prérequisitos para a sua luta por reconhecimento. Logo depois, se resgatará a noção de identidade pessoal enquanto uma importante categoria do reconhecimento. Em quarto lugar, será problematizada a unilateralidade do princípio de êxito como forma de tratar as desigualdades as quais os catadores estão submetidos. E, por último, se 
discutirá a estratégia do ambientalização do trabalho dos catadores.

Em síntese, a importância da realização deste debate reside no fato de que sem uma abordagem teórico-conceitual, não se pode sequer visualizar, nem tão pouco se efetivar estratégias políticas de enfrentamento às discriminações sociais. Para a compreensão dessas estratégias é fundamental importância a discussão de um conjunto de conceitos que possibilitem a interpretação dos fatores motivacionais das ações cotidianas dos catadores.

\section{Perspectiva dualista e unidade conceitual}

A ideia de reconhecimento parte da concepção de que esta noção comporta um princípio de igualdade socialmente compartilhado, e que em função do mesmo, as lutas por reconhecimento acabam por incorporar tanto as estratégias pelo direito de todos aos padrões de igualdade quanto aos conflitos para que as diferenças sejam reconhecidas e valorizadas (HONETH, 2007). No entanto, esta unidade teórica entre igualdade e diversidade pode ser desfeita ao se tematizar o reconhecimento através de uma abordagem dualista, tal como a proposta por Nancy Fraser (2006), dentro da qual as reivindicações de reconhecimento entram em choque com as reivindicações pela redistribuição da riqueza. A insuficiência desta argumentação consiste em acabar estabelecendo uma lógica contrassensual entre a distinção advinda da posição social e a igualdade de acesso à redistribuição de riquezas. Ao assim proceder, se busca comprovar a inexistência de um princípio de igualdade capaz de conduzir a ação dos sujeitos. Tal ausência faz com que a luta por reconhecimento seja uma "luta para marcar uma distinção que possibilite usufruir os ganhos materiais e simbólicos associados a uma posição diferenciada" (SILVA; MICHELOTTI, 2009, p. 452).

O problema é que ao se dar ênfase a determinados padrões de igualdade, materiais e simbólicos, se tende a desconsiderar as configurações da identidade dos sujeitos catadores, classificando a sua reafirmação como parte de uma estratégia de distinção fomentadora de desigualdades entre seus pares. Tal desconsideração é que abre um grande abismo entre as noções de distinção e igualdade (HONNETH, 2006, p. 91). Para além deste dualismo, a perspectiva advinda do debate teórico e estratégico proposto por Axel Honneth parte do pressuposto de que as próprias injustiças distributivas são fruto de uma falta de respeito, a qual pode ser tida como uma ameaça, institucionalmente ocasionada, às reivindicações por reconhecimento por parte dos sujeitos descontentes com as circunstâncias que ocasionam situações de injustiça (lbid., p. 92).

Honneth (2006) busca avançar na superação deste dualismo ao propor uma unidade de correspondência conceitual entre a ameaça identitária dos sujeitos - definida por ele como falta de respeito - e o rol de injustiças que impedem a concretização de relações igualitárias (Ibid., p. 92). Isso porque, para ele, a luta política dos sujeitos coletivos em sua busca por reconhecimento é motivada pela ameaça constante às suas identidades. Essa luta acaba por constituir, em função disso, um processo de questionamento às formas desiguais de acesso aos direitos relacionados à cidadania ${ }^{1}$.

Desse modo, para a consecução de uma estratégia de reconhecimento por parte dos catadores, esses devem buscar primeiramente a reafirmação de sua identidade contra à atribuição de uma alteridade negativa por parte de um longo histórico de discriminação vivenciado por estes indivíduos. É notória a forma como os catadores descrevem as experiências de discriminação, através das quais eles ilustram a realização de uma atividade de trabalho sistematicamente desqualificada por significações negativas a eles atribuídas através da precariedade das atividades primárias da reciclagem como a coleta ou a "catação" de materiais tidos, comumente, como lixo. Essas significações acabam

\footnotetext{
${ }^{1}$ Segundo Santos (2007, p. 17), as condições de possibilidade para o exercício da cidadania passam por um duplo movimento: primeiro, os sujeitos devem ser capazes de realizar satisfatoriamente um determinado processo interativo, e, segundo, os mesmos precisam obter, em função disso, o reconhecimento por parte dos seus concidadãos.
} 
por reforçar as más condições de vida e de trabalho dos catadores nos contextos urbanos. Os catadores se tornam, assim, simultaneamente, vítimas e protagonistas dos processos históricos que constituem a reciclagem (OLIVEIRA, 2010).

Neste caso, a insistência no estabelecimento de um pretenso dualismo perspectivista entre a reafirmação das diferenças identitárias e os direitos de participação na redistribuição de riquezas ocasiona uma ambiguidade teórica através da qual se desconsidera o processo de atribuição de uma alteridade negativa aos catadores, o que impede que os mesmos sejam reconhecidos enquanto sujeitos portadores de direitos.

Para a visualização de uma concepção estratégica de reconhecimento é preciso, em função dessa realidade, um conceito unitário e de síntese que possibilite a interpretação da luta política dos catadores em distintas esferas de reconhecimento. Antes de adentrar nisso, se faz necessário precisar de modo mais aprofundado o processo teórico para que sejam compostas categorias conceituais mais adequadas para esta discussão.

\section{Expectativas morais e luta por reconhecimento}

A ameaça à identidade dos catadores, em função de experiências de discriminação, é a origem do descontentamento social, a qual decorre de reiterados processos que expõem os catadores a uma "experiência de rechaço de sua ação" (HONNETH, 2003, p. 223). Os catadores passam a se compreender como alguém portador de um valor social menor do que haviam suposto previamente, os mesmos se vêem atingidos em seus ideais de ego (lbid.). Eles sentem que, por isso, estão comprometidas as suas expectativas normativas de reconhecimento enquanto sujeitos ativos, com as quais eles buscavam manter seu autorrespeito e sua autorrealização (Ibid.). Nesse sentido, para que essas ameaças identitárias, cujo resultado consiste em sofrimento e humilhação, possam ser convertidas em luta política, elas dependem das possibilidades de discernimento moral feitas por aqueles que foram atingidos pelas injustiças. Além do mais, as injustiças precisam ser apropriadas, em termos cognitivos, como motivos da necessária luta por reconhecimento (lbid., p. 224).

Para que seja possível tematizar e até reconhecer as ações e esforços estratégicos por parte dos catadores se torna preciso uma terminologia moral que permita identificar o descontentamento social. A percepção, e a consequente tematização da luta por reconhecimento prescinde, inclusive, dos debates travados em eventuais e possíveis esferas públicas (HONNETH, 2006, p.100). Isso porque, a maioria dos casos de sofrimento social cotidiano nem sequer chegam a ser conhecidos publicamente, e não quer dizer que não exista conflitos a cerca da sua justa resolução (Ibid., p. 95). A terminologia moral, que possibilita o esclarecimento dos conflitos, é, em si, o substrato desses mesmos conflitos por reconhecimento.

O que os sujeitos descontentes interpretam como injustas são as ações que violam o que eles acreditam serem reivindicações bem fundamentadas de reconhecimento social (HONNETH, 2006, p. 106). Em suma, a expectativa moral de reconhecimento encontra-se, estritamente vinculada ao processo intersubjetivo de formação de identidades. Assim, como forma de se obter um conceito estratégico e sintético de reconhecimento dos catadores é preciso que se torne efetivo o reconhecimento das suas reivindicações de identidade (Ibid., p. 104). Quando se desconsidera essa processualidade compartilhada entre os catadores, se acaba por inviabilizar a possibilidade mesma de conquista de reconhecimento por parte dos mesmos.

\section{Reafirmação da identidade de catador} como reconhecimento social

Existe uma relação direta entre o trabalho desenvolvido pelos catadores e a sua identidade pessoal. Nesse sentido, Honneth (2008a, p. 47) afirma muitos sujeitos coletivos derivam a identidade pessoal de seus membros a partir de seu papel no 
processo organizado de trabalho em uma determinada sociedade (Ibid.). Com isso, a compreensão dos conflitos dos catadores passa pela reafirmação da sua identidade pessoal, cuja consolidação acontece no interior do processo de trabalho nos ciclos básicos da cadeia produtiva da reciclagem. A luta por reconhecimento identitário diz respeito, assim, à valorização dos aspectos que conformam a personalidade dos indivíduos em questão, e não pode ser desvinculada das atividades laborais por eles exercida. Sendo, inclusive, a partir deste processo que muitos dos tradicionais movimentos de resistência operária conseguiram garantir a motivação necessária à busca de seus objetivos sociais e econômicos (HONNETH, 2006, p. 105).

Considerar a dialética entre uma estratégia de distribuição de riquezas provenientes do fruto do trabalho coletivo e a conformação de identidades pessoais faz com que o suposto dualismo entre igualdade e distinção perca sentido. Silva e Michelotti (2009, p. 450), em contraposição, sustentam que "alguns grupos têm buscado transcender os contornos identitários" ao perseguirem a ênfase histórica na igualdade. A insuficiência constatada nesse ponto reside no fato de que estes autores não deixam claro quais os grupos abriram mão de sua afirmação identitária. E mesmo se tal neutralização dos contornos identitários fosse possível, poder-se-ia afirmar, com alto grau de certeza, que isso se converteria em uma estratégia anuladora dos próprios sujeitos, precisamente em função das constantes ameaças de deterioração identitária e de atribuição de uma alteridade negativa por parte de outros sujeitos com os quais se entra em conflito. Tal processo de "desidentificação" viria a impedir, assim, que fossem criadas as condições necessárias tanto ao reconhecimento dos catadores quanto à sua participação na vida pública.

O que os autores em questão procuram fazer é inverter os termos da noção de reconhecimento, pois para eles esta noção deve ser inserida numa esfera universal de cidadania para que ela possa representar "um status que anteceda a conquista da autoestima pessoal ou dos direitos de um grupo específico" (SILVA; MICHELOTTI, 2009, p. 451). Dessa forma, a igualdade estaria consubstanciada na noção de uma cidadania plena (Ibid., p. 449). Esta por sua vez prescindiria de qualquer menção ao reconhecimento das diferentes identidades pessoais e coletivas. Honneth (2006, p.139) descarta essa suposta dispensa das configurações do processo de identificação dos sujeitos ao reafirmar que a finalidade da justiça social consiste em permitir a formação da identidade pessoal de todos os membros de uma coletividade. $\mathrm{O}$ autor sintetiza isso ao afirmar que "devemos generalizar nosso conhecimento das precondições sociais da formação da identidade pessoal em uma concepção que tenha o caráter de uma teoria da vida ética igualitária (Sittlichkeit)" (Ibid.). O termo alemão Sittlichkeit, traduzido para o português como "eticidade", se refere a uma ideia de "vida boa", a qual não pode ser esgotada nem por diversos pressupostos teóricos e tão pouco por várias evidências empíricas (Ibid., p. 141). No entanto, devese traçar um perfil do que seria esta concepção e como que ela é tornada hipoteticamente generalizável (Ibid.).

A concepção normativa dessa "vida ética igualitária", ou de "eticidade", proposta por Honneth (2006) com base na filosofia hegeliana, está fundamentada, deste modo, no processo de vinculação pleno e não distorcido entre a identidade pessoal interna e o reconhecimento social externo em suas distintas dimensões (WERLE; MELO, 2007, p. 14; SAAVEDRA; SOBOTTKA, 2008, p. 16). Sendo que a identidade pessoal, ou seja, a forma como o indivíduo se autocompreende enquanto um membro autônomo e individualizado de uma dada sociedade (Ibid., p.16) é o que reforça a ideia de que esta mesma identidade não pode ser constituída a partir de si mesma (self-constituted), tal como supunha a antiga tradição filosófica idealista, mas, que ela somente pode ser moldada por relações intersubjetivas presentes nas estruturas sociais (LUCKMANN, 2006).

Em se tratando dos catadores de materiais recicláveis, sua identidade pessoal encontra-se 
reiteradamente ameaçada por uma visão dicotômica que estabelece uma cisão entre os catadores organizados em associações e cooperativas com alguma estrutura de trabalho coletivo, e os catadores de rua e de lixões, através do uso dos termos de "reciclador" para os primeiros e de "catador" para os últimos. O primeiro termo possui um significado mais próximo ao empresário da reciclagem, e o segundo, ao sujeito discriminado e pouco reconhecido socialmente (OLIVEIRA, 2010, p. 84-87).

A partir dessas constatações, não se torna mais possível reduzir os termos deste debate simplesmente a formas de distinção relativas a um status atribuído a si pelos próprios sujeitos sem se conseguir compreender a importância que as identidades pessoais possuem para que se consiga obter padrões estáveis de reconhecimento (HONNETH, 2006, p. 192). Ainda mais quando se trata de uma população tal como a dos catadores, cujos padrões de reconhecimento ainda não se encontram dotados de estabilidade. Isso contribui para a referida cisão em sua identidade e uma ameaça constante a ela. Desconsiderar tal ameaça, e negligenciar a tematização dos processos que constituem a identidade pessoal catadores, em prol de um suposto igualitarismo, consiste em uma grande insuficiência, a qual impossibilita a compreensão de uma estratégia política de reconhecimento viável a ser protagonizada pelos catadores.

\section{A unilateralidade do principio de êxito}

\section{frente a igualdade do processo de reconhecimento jurídico}

Honneth (2006, p. 113) teoriza três esferas de reconhecimento através das quais os sujeitos aprendem a referirem-se a si mesmos. Estas são, respectivamente, o amor, a igualdade e o êxito. Abordadas de modo breve e sintético, a esfera do amor diz respeito às práticas de afeto e de preocupação mútuas em que os sujeitos se tornam capazes de compreenderem-se como indivíduos dotados de necessidades próprias. Dentro da esfera da igualdade estão situadas as relações jurídicas que se desenvolvem segundo a igualdade de direitos. E a última das esferas de reconhecimento é a que compreende a interpretação unilateral do princípio do êxito individual na qual os sujeitos procuram entender a si mesmos e os outros como possuidores de habilidades e talentos valiosos para a sociedade. Estas esferas constituem as perspectivas normativas que fundamentam as argumentações dos sujeitos em suas estratégias pela conquista de reconhecimento (Ibid.). As formas vigentes de reconhecimento podem não ser suficientes e nem adequadas, sendo necessário, por causa disso, empreender conflitos para ampliá-las e aperfeiçoá-las. Estas esferas representam modelos de interação dentro dos quais se expressa a intersubjetividade dos sujeitos sociais e políticos, portanto são inseparáveis inclusive das tentativas de delimitações classificatórias entre elas (lbid.).

No entanto, o princípio individualista do êxito é o princípio pelo qual a sociedade capitalista procura justificar moralmente a desigualdade na distribuição de oportunidades e dos bens vitais aos indivíduos no ambiente de mercado (HONNETH, 2006, p. 117). Sendo nesta esfera que ocorrem os processos de estratificação da sociedade. Porém, para Honneth (Ibid., p. 121) há duas formas de se demarcar o reconhecimento das situações vitais particulares aos sujeitos dentro da esfera do êxito. A primeira está em conformidade com 0 apelo às habilidades pessoais como uma capacidade específica do êxito. Essa forma de valoração é o que demarca os limites entre as profissões e a divisão social do trabalho como um todo. Tais valorações podem estar repletas de preconceitos a cerca dos limites das capacidades dos sujeitos (lbid.). Para contrapor essas formas distorcidas de valoração é que se deve garantir direitos sociais a todos cidadãos com a finalidade de satisfazer suas necessidades básicas, possibilitandoIhes, assim, uma margem de autonomia frente à mesma esfera do êxito. Ou seja, se deve oportunizar aos sujeitos a possibilidade de mobilizar com razão o princípio da igualdade situado na esfera do reconhecimento jurídico enquanto uma forma de acionar a demanda moral de bem-estar 
socioeconômico destinada a todos os membros de uma sociedade (lbid.).

A complementaridade entre a esfera do êxito e a esfera da igualdade é o que pode evitar que os direitos sociais não venham a ser restringidos aos direitos do lugar onde os sujeitos atuam dentro de um processo de produção. Entretanto, quando se trata única e exclusivamente do princípio do êxito, este condiciona as tábulas de classificação e os esquemas de interpretação que determinam as atividades profissionais. Com o princípio de êxito é que pode-se definir quais atividades são entendidas como trabalho, bem como os limites até onde pode chegar o reconhecimento dessas atividades (HONNETH, 2006, p.122).

No momento em que os grupos ou setores sociais, que lutam por uma maior estima social, passam a questionar e a deslegitimar os modelos de valoração vigentes no princípio de êxito é que ocorrem as tramas de conflito cotidiano da reprodução da divisão capitalista do trabalho em contraposição às lutas por distribuição submetendoas a um processo permanente de negociação (2006, p. 123). Esta conflitualidade é fundamental, pois não existe, segundo Honneth (lbid.), uma forma de avaliação desses conflitos meramente técnica, ou seja, neutra com relação aos valores socioculturais. Tais conflitos por redistribuição dentro da valoração do êxito das categorias de trabalho são de natureza pré-política e somente se convertem em lutas políticas quando os setores afetados se reúnem para questionar a ordem de estima social dominante (HONNETH, 2006, p.123).

Contudo, o questionamento das relações desiguais neste contexto é enfraquecido em função de uma identidade cindida por parte dos catadores. Esta fragmentação identitária dá início à constituição de um processo, cujas relações são impossibilitadas de serem apreendidas através de critérios éticos e normativos. Concordando com as afirmações de Silva e Michelotti (2009, p. 460), o catador quando concebido como "reciclador" deve "empreender uma atitude pragmática o suficiente para se adaptar às exigências que forem necessárias para sobreviver a um mercado cada vez mais competitivo". Neste sentido, as considerações de que o "reciclador" deve "interiorizar valores e normas necessários para tanto e adquirir os recursos para que possa se tornar autônomo a ponto de não precisar mais ser economicamente 'ajudado'” (SILVA; MICHELOTTI, 2009, p. 460) vão ao encontro das idéias de Honneth (2006, p. 124) de que não é possível e nem aconselhável isolar os fatores econômicos ou sistêmicos dos fatores morais.

Entretanto, o referido isolamento acontece, porque tanto a delimitação das fronteiras profissionais como as regras de remuneração são condicionadas por regras de eficiência presentes nas perspectivas de valoração a cerca do mundo social. Assim, quando é constatada uma imanência entre as dimensões econômicas e morais, as quais não podem ser separadas nem conceitualmente, pode-se constituir uma perspectiva teórica capaz de contribuir na compreensão estratégica de como os catadores constituem suas expectativas éticas e normativas, as quais compõem suas convicções e seus motivos, de modo simultâneo, para a potencialização do conflito visando o reconhecimento.

Deixado claro isso, não é correto, pois, restringir o reconhecimento apenas a uma dimensão cultural delimitadora de status independente da dimensão da justiça econômica tal como apregoam Silva e Michelotti (2009, p. 450). Isso porque, as lutas por distribuição de riquezas são moldadas por valorações morais sobre necessidades, reivindicações ou habilidades realizadas diretamente pelos sujeitos sociais concretos. As dimensões de distinção e igualdade são intrínsecas ao mesmo processo de reconhecimento (HONNETH, 2006, p. 125).

Partindo dessa imanência, pode-se conceber que a aplicação arbitrária e unilateral do princípio do êxito pode ser estrategicamente contrarrestada ao fazer com que se acione a esfera de igualdade jurídica. Para a efetivação disto, Honneth (2003, p. 179) propõe que a noção de direito seja um fator central para a dotação de estabilidade aos padrões constantes nas diferentes esferas de reconhecimento. 
As relações jurídicas não emergem, contudo, unicamente das estruturas do poder judiciário do Estado, mas sim, das relações sociais estabelecidas entre os indivíduos (lbid.).

O processo pelo qual o catador passa a reconhecer a si mesmo como detentor de direitos se inicia, conforme F (catador, 28 anos), quando ele...

...parte pra reivindicar alguma coisa com propriedade, assim, né, com fundamento de dizer que a gente tem direitos... que a gente é isso... que a gente defende isso... aí tu tocas na ferida, né... daí o governo, ele só tenta abafar o preconceito e toda a opressão que se passa, né, como daquela forma superficial que eu te falei... ah é bonito, é legal. Tá, realmente, é bonito, é legal, mas a gente quer mais, a gente quer a coisa concreta também acontecendo... (OLIVEIRA, 2010, p. 103-104)

Os dizeres de F. traduzem bem a complexidade que envolve as expectativas de conquista de direitos. Este conjunto de expectativas constitui, a partir de tal complexidade, uma das bases de organização da ação coletiva dos catadores que auxiliam para que eles consigam situar-se em relação aos demais atores através da reivindicação pelos seus direitos.

As expectativas nutridas em função da conquista de direitos são, deste modo, a possibilidade que os catadores possuem de reconhecerem-se enquanto sujeitos portadores de tais direitos. Este processo Ihes proporciona, assim, a oportunidade de resgate de sua identidade através do estabelecimento de demandas. Tais demandas são, por sua vez, interpretadas e traduzidas reflexivamente em pautas políticas reivindicativas que apontam para uma mudança da situação social na qual os catadores se encontram.

Ao trazer a discussão sobre a luta por direitos como parte fundamental das estratégias por reconhecimento não é possível entender a ação coletiva dos catadores por reconhecimento como não sendo orientada por um princípio de igualdade. Isso porque, os catadores lutam por reconhecimento jurídico igualitário como forma de compensação às desigualdades intrínsecas ao princípio de êxito individual dentro das relações de reconhecimento.
Esta luta no interior destas esferas é mediada por relações de conflito ocasionadas em virtude da ação moral desses trabalhadores. Assim, para que os direitos dos catadores sejam juridicamente reconhecidos na sociedade, são necessárias prerrogativas morais que são passiveis de se converterem em possibilidades estratégicas.

\section{Justificativa moral e o aperfeiçoamento} das perspectivas estratégicas

As reivindicações dos catadores não podem ser compreendidas unicamente como sendo de natureza pragmática, porque, se assim o forem, acabam por encobrir as expectativas éticas que os sujeitos desenvolvem a respeito do mundo em que vivem. Tal forma de compreensão impossibilita a compreensão dos sujeitos como atores morais (HONNETH, 2006, p. 102). As perspectivas morais e os critérios normativos surgem de reivindicações contextualizadas através das interações sociais destes atores. $E$ quando esses critérios são frustrados ou violados é que são geradas as condições para que seja constituído o descontentamento ou o sofrimento social (Ibid., p. 103), o que garante que os sujeitos tenham a certeza de que a sociedade está fazendo algo injusto e injustificável (lbid.).

Há uma convicção de legitimidade que se orienta por conseqüências morais advindas de procedimentos utilizados com a finalidade de justificativa de certas decisões políticas. Assim para Honneth (2006, p. 105), a forma como ocorrem as mediações entre as normas que justificam a ordem pública garantem uma estabilidade relativa às reivindicações advindas dos sujeitos. Tal justificativa moral contribui para o aperfeiçoamento das perspectivas políticas dos sujeitos em luta por reconhecimento (lbid., p. 90).

Esse processo de justificação auxilia, por sua vez, na elaboração de uma gramática ética capaz de compor uma linguagem moral comum motivadora das lutas sociais (WERLE; MELO, 2007, p. 16). Munidos disso, os catadores conseguem converter 0 
sentimento de desrespeito em uma base motivacional para as suas mobilizações sociais e políticas, através das quais eles conseguem expressar um determinado ponto de vista generalizável a partir das suas próprias concepções normativas (lbid.).

A codificação dessa gramática acaba se tornando um fator de motivação do próprio processo de organização do MNCR, pois remete a uma forma de vinculação entre as experiências passíveis de serem agrupadas em categorias operacionais que conferem sentido intersubjetivo a essas mesmas experiências (BERGER; LUCKMANN, 2008, p. 59). Para tanto, é preciso interpretar as experiências dos catadores em termos de desenvolvimento de um processo organizacional levado a cabo por eles mesmos. Logo abaixo, podem ser visualizados alguns aspectos do processo constitutivo da organização dos catadores através do seguinte fragmento extraído da primeira cartilha de formação nacional do MNCR:

Após a realização de dezenas de encontros de representantes dos estados do Brasil onde estamos organizados, dois congressos de abrangência latino-americana, definimos um conjunto de critérios básicos para estruturação da organização do movimento ao qual chamamos de "bases de acordo"; um conjunto de códigos de conduta ética e valores que chamaremos de princípios orientadores do movimento e também um conjunto de metas de curto e largo prazos que temos como objetivos do MNCR (MNCR, 2005, p. 05).

Este excerto torna possível perceber que as interações entre os catadores se baseiam em certas limitações normativas advindas dos contextos sociais que se refletem nos ideais de valor moral que se institucionalizam, e que, por isso, acabam por submeter as próprias interações desses sujeitos (HONNETH, 2006, p. 185). Tal repertório de princípios normativos intrínsecos às relações sociais acaba por definir o horizonte de linguagem que dá forma aos seus pensamentos e sentimentos morais (Ibid., p. 186).

7 A estratégia de ambientalização para 0 reconhecimento social dos catadores
Nesta última parte, é preciso discutir a importância ambiental do trabalho dos catadores. Silva e Michelotti (2009, p. 461) classificam a estratégia de ambientalização da atividade social, política e produtiva desses sujeitos como mais uma forma de aprofundamento de desigualdades, pois a mesma faria parte de uma estratégia de distinção contraigualitária e que impediria que os catadores fossem reconhecidos como cidadão, tal qual os demais, com direitos iguais garantidos a todos.

Antes de tudo, é preciso deixar claro que Honneth (2003, p. 200) concebe a compreensão cultural, que uma sociedade atribui a si mesma, como um fator predeterminante para o estabelecimento dos critérios de avaliação sobre as capacidades e as realizações dos sujeitos em suas ações para implementar os valores culturalmente definidos, os quais acabam por constituir objetivos coletivamente compartilhados entre os sujeitos (lbid.).

Neste sentido, ao traçarem as suas estratégias de ação, os catadores não podem deixar de considerar tanto a compreensão, os critérios e os objetivos definidos de maneira intersubjetiva e coletiva na cultura da sociedade na qual vivem, trabalham e atuam social e politicamente para a efetivação de uma estratégia de reconhecimento. Neste ponto, é de grande necessidade levar em consideração que o crescimento da importância atribuída ao encaminhamento adequado da questão ambiental figura como um grande objetivo comum das sociedades modernas. Não somente nas instituições, mas, no interior da própria cultura social, o alto grau de valoração que ganhou essa temática contribui para que seja criado, todo um campo de relações propício para que se constituam critérios de avaliação positiva a cerca das realizações e das potencialidades dos catadores e de seu papel para a consecução de um objetivo socialmente compartilhado. Como se referem criticamente Silva e Michelotti (2009, p. 456) quando enfatizam que o catador almeja se tornar parte de...
[...] uma categoria profissional cujo serviço prestado possui um caráter de grande utilidade pública, passível de ser reconhecido pela importância ambiental que lhe é intrínseca, o que impõe à sociedade a 
necessidade de valorizar a sua profissão (lbid.).

A citação acima comprova que os referidos autores reconhecem que a implementação prática dos objetivos de uma sociedade confere prestígio e reputação aos indivíduos como forma de reconhecimento que estes demandam para a sua autorrealização.

Nesse sentido, se torna possível constatar que uma tensão impregna as formas modernas de organização da estima social submetendo-as a um conflito de ordem cultural (HONNETH, 2003, p. 206). Nesse ponto, é importante frisar que o que ocorre é um conflito simbólico, para o qual os distintos grupos sociais buscam interpretações díspares como meios de elevar sua força em referência às finalidades gerais de uma sociedade (lbid., p. 207). Dentro de uma deste tipo de conflitualidade, é que os catadores procuram a consolidação de uma estratégia de fortalecimento da atividade e da sua identidade, enquanto uma forma de elevar a estima social destes sujeitos.

Para que os catadores possam ser reconhecidos como iguais, antes é preciso enfrentar os critérios de avaliação que os julgam como inferiores, e disseminar, simultaneamente, uma outra forma de valoração da estima destes atores. Neste sentido, a estratégia de ambientalização do trabalho dos catadores cumpre um papel de extrema importância como um instrumental a serviço da luta pelo reconhecimento das ações sociais, políticas e produtivas desses sujeitos.

\section{Considerações finais}

Cabe destacar, à guisa de finalização deste artigo, quatro pontos fundamentais sobre o debate acerca das estratégicas de reconhecimento dos catadores organizados no MNCR. O primeiro aspecto a ser destacado é que não é possível abordar o reconhecimento como uma categoria desprovida de uma base moral e identitária como se fosse uma simples questão de atribuição de status conformador de distinções societárias. Isso porque, tanto as perspectivas morais quanto aquelas referentes à identidade dos indivíduos são de fundamental importância para a obtenção de padrões estáveis de reconhecimento. Insistir na desconsideração desses fatores significa incorrer no obscurecimento dos princípios que norteiam os conflitos reais dos catadores na sociedade. Em segundo lugar, é possível constatar que a luta dos catadores do MNCR por reconhecimento é uma forma de superação das desigualdades próprias da consecução de êxito nas relações de mercado.

Em terceiro, para que a participação social e política dos catadores seja efetiva, é preciso que ela aponte para a autonomia destes sujeitos, em termos de uma autorrelação moral e identitária através do reconhecimento mútuo. Ou seja, não é possível haver participação sem a ação e sem conflito social como um mediador necessário para disseminar uma gramática moral. E por último, para que os catadores possam ser reconhecidos como iguais é necessário enfrentar os critérios culturais de avaliação que os inferiorizam com relação aos demais. Dessa forma, a constituição de estratégias para este tipo de luta é de fundamental importância para que se concretizem outras formas de valoração social destes sujeitos.

Com base nestes quatro pontos fundamentais para se aplicar da teoria do reconhecimento para a compreensão das estratégias do MNCR, pode-se ter claro que as perspectivas estratégicas traçadas por este movimento devem levar em consideração o reconhecimento das identidades e modos de vida dos catadores para que se torne possível a concretização de critérios de interpretação das potencialidades desses sujeitos livres de distorções discriminatórias.

Por sua vez, esta forma de compreensão do processo estratégico em debate propicia um processo de questionamento à dicotomia entre igualdade e distinção. Pois, nesta outra forma de conceber, os sujeitos se encontram constantemente conectados pelas relações intersubjetivas, sendo que eles reciprocamente podem visualizar na autonomia do outro o pressuposto necessário para sua própria realização enquanto indivíduo. Esse outro modo de abordar o reconhecimento concebe o mesmo 
enquanto igualdade e diferença simultaneamente concretizadas dentro de uma noção de justiça social. A partir disso, é que podem ser estruturados os aspectos normativos e intersubjetivos mínimos entre os catadores relacionados às suas reivindicações morais por igualdade à sua reafirmação de sua distinta identidade de modo simultâneo e indissociável.

Assim, a luta por redistribuição de riquezas econômicas imprescinde da afirmação da identidade pessoal do catador, advinda de seu processo de trabalho e de produção. Deste modo, o catador ao lutar contra as discriminações acaba por evocar em suas estratégias a luta por direitos em âmbito jurídico como forma de compensação às desigualdades intrínsecas ao princípio de êxito individual apregoado pelas relações capitalistas de mercado. Isso faz com que a ação coletiva dos catadores em sua busca por reconhecimento seja plenamente pautada por um princípio de igualdade através da reafirmação da sua diferença.

\section{Referências}

BERGER, Peter L. e LUCKMANN, Thomas. A construção social da realidade: tratado de sociologia do conhecimento. Petrópolis, RJ: Vozes, 2008.

FRASER, Nancy; HONNETH, Axel. ¿Redistribución o reconocimiento? A Coruña: Paideia, 2006.

HONNETH, Axel. La justicia social en la era de la política de la identidad: redistribución, reconocimiento y participación. In. FRASER, Nancy; HONNETH, Axel. ¿Redistribución o reconocimiento? A Coruña: Paideia, 2006.

La cuestión del reconocimiento: réplica a la réplica. In. FRASER, Nancy; HONNETH, Axel. ¿Redistribución o reconocimiento? A Coruña: Paideia, 2006.

Luta por reconhecimento: a gramática moral dos conflitos sociais. São Paulo: Ed. 34, 2003.

Observações sobre a reificação. Civitas, v. $8, n^{\circ} 1$, p. $68-79$, jan.-abr. 2008b.

Redistribución como reconocimiento: respuesta a Nancy Fazer. In. FRASER, Nancy; HONNETH, Axel. ¿Redistribución o reconocimiento? A Coruña: Paideia, 2006.
Sofrimento de indeterminação: uma reatualização da filosofia do direito de Hegel. São Paulo: Esfera Púlica, 2007.

Trabalho e reconhecimento: tentativa de uma redefinição. Civitas, v. 8, n 1, p. 46-67, jan.-abr. $2008 a$.

LUCKMANN, Thomas. Personal Identity as a Sociological Category. Zagreb, 2006. Disponivel em: <http://www.scienzepostmoderne.org/OpereComplete /LuckmannThomasPersonalldentitySociologicalCateg ory.pdf>. Acesso em 23/03/2015.

MARTINS, Clitia Helena B. Trabalhadores na reciclagem do lixo: dinâmicas econômicas, socioambientais e políticas na perspectiva de empoderamento. Porto Alegre, RS, Teses FEE n. 5, 2005.

MICHELOTTI, Fernando C. Catadores de "lixo que não é mais lixo": Um estudo da dimensão do reconhecimento social a partir de sua experiência de organização coletiva no Rio Grande do Sul. Dissertação de mestrado, PPGS - UFRGS. Orientador: Prof. Dr. Raúl Enrique Rojo. Rio Grande do Sul, 2006.

MOVIMENTO NACICONAL DOS CATADORES DE MATERIAIS RECICLAVEIS (MNCR). Cartilha de formação. São Paulo: 2005.

Cartilha de formação \#1: Caminhar é resistir. 2 ed. São Paulo: 2010.

NEVES, Paulo. S. Direitos humanos e cidadania simbólica no Brasil. p. 203-223. In: LYRA, R. P. (Org.). Direitos humanos: Os desafios do século XXI. Uma abordagem interdisciplinar. Brasília: Brasília Jurídica, 2002.

OLIVEIRA, Cristiano B. A questão social da reciclagem: um estudo sobre reflexividade, desigualdade e articulação de redes sociopolíticas no Rio Grande do Sul. Dissertação de mestrado, PPGCS-PUCRS. Orientador: Prof. Dr. Emil Albert Sobottka. Rio Grande do Sul, 2010.

SANTOS, Hermílio. Interação social, novas mídias e cidadania: apontamentos para a análise da recomposição de identidades ameaçadas. Civitas, v.7, n.2, julho a dezembro de 2007.

SILVA, Marcelo K., MICHELOTTI, Fernando C. Conflitos por reconhecimento na modernidade periférica entre a igualdade e a distinção. Política \& Sociedade. № 14 - abril de 2009.

SOBOTTKA, Emil A. e SAAVEDRA, Giovani $A$. Introdução à teoria do reconhecimento de Axel Honneth. Civitas, v. 8, n 1, p. 9-18 jan.-abr. 2008.

SOUZA, Jessé. Uma teoria crítica do reconhecimento. Lua Nova. São Paulo, n. 50, p. 133-158, 2000. 
A construção social da subcidadania: para uma sociologia política da modernidade periférica. Belo Horizonte: Editora UFMG; Rio de Janeiro: IUPERJ, 2003.

A gramática social da desigualdade brasileira. Revista Brasileira de Ciências Sociais. São Paulo. V. 19, n. 54, p. 79-96, 2004.

WERLE, Denílson L. e MELO, Rúrion S. Introdução: teoria crítica, teorias da justiça e a "reatualização" de Hegel. In: HONNETH, Axel. Sofrimento por indeterminação: uma reatualização da filosofia do direito de Hegel. São Paulo: Esfera Pública, 2007. 